Eixo Temático: Relação entre Ciência, Educação e Cultura

\title{
ET-05-008 \\ MEIO AMBIENTE E A EDUCAÇÃO: PERCEPÇÃO AMBIENTAL DE ESTUDANTES DE GEOGRAFIA
}

Gustavo Kim Rodrigues Agra1, Gleydson Kleyton Moura Nery²

${ }^{1}$ Graduando em Química Industrial, Universidade Estadual da Paraíba - UEPB, Rua Baraúnas 351, Bairro Universitário, Campina Grande, PB.

${ }^{2}$ Graduando em Ciências Biológicas, Universidade Estadual da Paraíba - UEPB, Rua Baraúnas 351, Bairro Universitário, Campina Grande, PB.

http://dx.doi.org/10.21472/congrebio2016.et-05-008

\section{RESUMO}

A questão ambiental é alvo de grandes discussões que cada vez mais se faz necessário sua difusão, assim a educação apresenta um papel fundamental nessa tarefa, pois surge a necessidade de entender como a questão ambiental se relaciona com a educação. E, uma das formas de evidenciá-la é por meio da percepção ambiental que apresenta como os indivíduos vê, compreende e se comunica com o ambiente, considerando assim as influências ideológicas de cada sociedade. Com isso o presente trabalho objetivou-se em avaliar a percepção ambiental dos discentes do curso de geografia da Universidade Estadual da Paraíba em uma perspectiva de abordagem reflexiva e desafiadora dos conceitos de meio ambiente ao longo da formação acadêmica. Este trabalho foi realizado com cunho qualitativo descritivo-exploratório, sendo desenvolvido entre o período de março à abril de 2015 na Universidade Estadual da Paraíba Campus I, Campina Grande, onde foram aplicados 30 questionário com discentes do curso de Geografia, que durante sua formação deve deter conceitos da educação ambiental e posteriormente realizou-se uma análise qualitativa na qual se identificou quais as percepções que os alunos de geografia têm acerca do meio ambiente e das aulas ministradas sobre meio ambiente no decorrer do curso. Na análise dos dados foi observado que a percepção ambiental dos alunos ainda precisa de uma educação ambiental para seu aperfeiçoamento e no que diz respeito às aulas no decorrer do curso ainda podem ser mais contextualizadas e prezar para o desenvolvimento de novas metodologias que atendam afetivamente essas questões. Conclui-se que o ensino é eficiente, mas precisa de algumas adequações no que diz respeito às questões ambientais para favorecer um uso sustentável dos recursos ambientais e alcance maior na sensibilização social.

Palavras-chave: Educação ambiental; Impacto ambiental; sustentabilidade.

\section{INTRODUÇÃO}

A questão ambiental é alvo de grandes discussões em torno do país e, cada vez mais, faz-se necessário à difusão do conhecimento dessa questão, na sociedade. Dessa forma, torna-se interessante saber o que a população ou parte dela compreende por meio ambiente e como este conceito está sendo abordado nas escolas, universidades e instituições de ensino em geral. Isso só é possível através da análise da a percepção ambiental que é definida como as formas que o indivíduos vê, compreende e se comunica com o ambiente, considerando assim as influências ideológicas de cada sociedade (ROSA e SILVA, 2002).

Portanto, a educação apresenta um papel fundamental, pois surge a necessidade de se buscar entender como a questão ambiental se relaciona com a educação (BORTOLOZZI e PEREZ FILHO, 2000). Contudo, desafios são encontrados ao longo do desenvolvimento do 
ensino-aprendizagem de inúmeras temáticas inclusive da Educação ambiental, assim como cita Brügger (1994), sendo a sociedade considerada "não ambiental”, pois existe um caráter técnico do pensamento industrial, que acaba por influenciar na educação. Dessa forma, a educação brasileira e sua política não correspondem aos anseios de um ensino de qualidade que aponta além de uma falta de percepção das relações entre os objetivos da educação e os do ensino da Geografia, como também aqueles vinculados à questão ambiental. Isto porque, tanto a educação como um todo, como o ensino da Geografia em particular deveriam proporcionar o desenvolvimento da cidadania de seus educandos, para uma participação mais efetiva na busca de políticas ambientais mais justas.

Sabendo que, a questão ambiental contribui importantemente em repensar a própria universidade exigindo um paradigma que seja capaz de dar conta da sua complexidade histórico natural. Se a realidade é dissecada em partes pela departamentalização cartesiana da universidade, o que a prática da extensão universitária coloca é exatamente o professor/pesquisador em contato com a realidade tal como ela é, isto é, um todo complexamente estruturado onde o natural e o social não estão dissociados (Gonçalves, 1990). Não diferente deste cenário o professor de geografia terá que envolver este tema em sala de aula para a formação de futuros cidadãos ciente sobre as questões ambientais. Por isso, a importância de avaliar a percepção ambiental dos graduandos em Geografia (licenciatura).

Por isso, resolvemos verificar a percepção ambiental de alguns estudantes de graduação da Universidade Estadual da Paraíba - UEPB, neste caso dos estudantes do curso de licenciatura em geografia. Visto que o mesmo trata das questões ambientais em alguns pontos nos conteúdos programáticos do ensino fundamental e médio. Ademais, sabe-se que Meio Ambiente é um tema transversal que deve ser problematizada em todas as disciplinas, dessa forma os licenciando de geografia devem está preparados e fundamentados para tal.

\section{OBJETIVO}

\subsection{Geral}

Avaliar a percepção ambiental dos discentes do curso de geografia da Universidade Estadual da Paraíba em uma perspectiva de abordagem reflexiva e desafiadora dos conceitos de meio ambiente ao longo da formação acadêmica.

\subsection{Específicos}

- Conhecer as principais percepções dos discentes sobre a caracterização do meio ambiente.

- Avaliar as principais questões ambientais retratadas pelos alunos em correlação a sua formação acadêmico-profissional.

- Identificar se há distinções entre as percepções dos períodos inicias e finais do curso.

\section{METODOLOGIA}

\subsection{Tipo de estudo}

O estudo é exploratório e descritivo, portanto, trata-se de uma pesquisa empírico descritiva, que, segundo Xavier (2010), é “Aquela que intenciona observar o fenômeno, descrevê-lo, registrar suas características, mensurá-lo, classificá-lo, sem que haja qualquer interferência do pesquisador nesse processo".

Quanto à forma de abordagem do problema a pesquisa é qualitativa, que, de acordo com Motta-Roth e Hendges (2010), trata-se de explorar a qualidade do vínculo estabelecido entre as ações empreendidas no evento e o tema / problema em investigação. 


\subsection{Campo e participantes da pesquisa}

A pesquisa foi realizada na Universidade Estadual da Paraíba - UEPB, campus de Campina Grande. Os participantes da pesquisa foram discentes de ensino superior da Universidade Estadual da Paraíba (UEPB), sendo: os discentes integrantes do período inicial (15 alunos) e final do curso (15 alunos). Ressalta- se, também, que apenas 46,66\% dos participantes moram na cidade em que se localiza o campus de estudo, os outros $53,33 \%$ são de cidades circunvizinhas, como Aroeiras, Barra de Santana, Boqueirão, Cubati, Esperança, Fagundes, Ingá, Massaranduba, Remígio e Puxinanã.

\subsection{Levantamentos de dados}

Para levantamento de dados foi proposto um questionário aplicado durante o mês de abril de 2016, estruturado por questões discursivas e objetivas, do tipo reflexiva, no intuito de os discentes não só expressassem suas respostas como também serem provocados e desafiados a refletir sobre suas atitudes e suas perspectivas sobre a temática ambiental ao longo de sua vida e sua formação acadêmica-profissional.

O questionário estrutura-se em duas partes: a correlação do meio ambiente e o comportamento da população e a correlação entre os fundamentos e a relevância que é dada a temática no decorrer do curso.

O presente estudo ocorreu segundo os requisitos básicos da Resolução 466/12 do Conselho Nacional de Saúde, Ministério da Saúde do Brasil. Onde, para a participação na pesquisa os entrevistados foram previamente esclarecidos quanto a pesquisa e seus objetivos e questionados sobre a possibilidade de participação livrando de possíveis riscos, fins lucrativos ou divulgação de imagem.

\subsection{Análise dos dados}

Os dados foram analisados qualitativamente através da análise de conteúdo (Bardin, 2009) através das respostas obtidas pelos discentes. Foram analisamos separadamente as respostas obtidas pelos discentes do período inicial do curso e do período final do curso, tendo por intuito relevar o desenvolvimento dos conceitos sobre a educação ambiental ao longo das formações. As percepções foram analisadas inicialmente em uma perspectiva de relação entre os discentes e o meio ambiente e em um segundo momento a análise das ideias da formação dos discentes em meio aos conceitos das disciplinas que envolvem a descrição e compreensão do meio ambiente e suas relações.

Tabela 1. Categorias das representações das percepções do meio ambiente utilizadas na análise de dados.

\begin{tabular}{ll}
\hline Categorias & Descrição \\
\hline Romântica & $\begin{array}{l}\text { Visão de "super-natureza”. Onde ilustra a natureza como grandiosa, harmônica, } \\
\text { intocada, estática e equilibrada. Neste contexto o homem apresenta-se isolado e } \\
\text { não inserido. Aponta uma visão dualista, homem vs. Natureza. }\end{array}$ \\
Visão da natureza como a fornecedora de recursos as comunidades de seres \\
vivos. Neste contexto, o homem apresenta inserido e o principal agente \\
extrativista e beneficiado, apontando uma perspectiva antropocêntrica. \\
Visão holística que abrange um totalidade complexa que inclui os fatores \\
naturais e antropocêntricos, resultando em uma relação entre os fatores bióticos, \\
abióticos e socioeconômicos culturais. \\
Visão simplificada através dos aspectos biológicos e abióticos (físicos e \\
químicos). Ignorando a complexa relação entre o meio e os demais sistemas \\
biológicos, sociais, econômicos e culturais. \\
Visão histórico-cultural, na qual o homem e a paisagem antropológica são \\
integradores da natureza. Ilustrando o homem muitas vezes como o principal \\
causador de impactos no ambiente.
\end{tabular}


Onde a análise das concepções de meio ambiente foi baseada nas categorias representativas das concepções sumarizadas na Tabela 1. Sendo as categorias, consideradas significativas para sistematizar as concepções de meio ambiente reveladas pelos discentes pesquisados, baseadas nas proposições de Reigota (1995), Brügger (1999), Tamaio (2000) e Fontana et al. (2002).

\title{
4. RESULTADOS E DISCUSSÃO
}

Nas respostas obtidas podemos perceber:

Na primeira questão perguntava "o que é o meio ambiente para você".

Foi observado que 56,66\% dos investigados apresentaram uma concepção enquadrada na categoria reducionista; $26,66 \%$ na categoria abrangente; $10 \%$ na categoria socioambiental e $6,66 \%$ na categoria utilitarista. Segundo as citações, muitos alunos graduandos de geografia não se vêm enquadrado no meio ambiente e não expressam suas relações com o mesmo por que se veem omissos das relações pertinentes ao ambiente, deixando de singular seus atos como possível influencia no comportamento ambiental. Como exemplo de algumas definições, segue as citações abaixo, em que E1 refere-se ao primeiro participante, E2 ao segundo, E3 ao terceiro e assim por diante. Q01 e Q02 especifica se o participante está no período inicial ou no final.

\author{
"Meio ambiente é todo espaço na terra" (E2: Q01; E5: Q01) \\ "Meio ambiente é um espaço natural” (E3: Q01; E7: Q01) \\ “Todo o espaço terrestre” (E6: Q01; E10: Q01) \\ “É um ambiente natural” (E13: Q01; E13: Q01; E8: Q02; E13: Q02)
}

Porém, ao analisarmos separadamente os graduandos do $2^{\circ}$ período com os do $7^{\circ}$ período. Percebe-se que no segundo período $73,3 \%$ dos alunos se enquadram na categoria reducionista e $13,3 \%$ na categoria abrangente. No sétimo período, $40 \%$ se enquadram tanto na categoria reducionista como na abrangente. Nesse sentido, percebemos que no decorrer da graduação os alunos puderam observar em parte os meandros de sua vivência no meio ambiente, ou seja, se viram enquadrados no meio ambiente, apesar de que para o alcance da percepção integral de todos não observamos o mesmo comportamento. Com isso, o curso forneceu em parte subsídios para melhoria da noção e da qualificação do meio ambiente na concepção dos alunos.

Outro fato interessante é a presença da palavra espaço nas definições para meio ambiente, em que quase $70 \%$ das respostas obtidas (20 afirmativas) tinham o seu comparecimento. Isso se deve ao termo "espaço" ser empregado constantemente durante as disciplinas no decorrer de todo o curso. Pois, segundo Bezerra \& Gonçalves (2007), as pessoas tendem a utilizar termos mais frequente do seu dia-a-dia e formulado em sua concepção para descrever algo que não está totalmente formulado em seu cognitivo, neste caso o meio ambiente. Assim, tornou-se mais propício à associação da palavra meio ambiente com o termo espaço nas respostas encontradas.

Na segunda questão perguntava "Em sua visão, quais são os principais problemas ambientais?”.

Nesta questão os alunos estavam livres para citar quantos problemas ambientais quisessem. Acerca desses problemas, vinte e um (70\%) alunos disseram que o principal problema ambiental é o desmatamento; dezoito (60\%) disseram que é a poluição; doze (40\%) elencaram ser a destinação incorreta dos resíduos sólidos; sete $(23,33 \%)$ apontaram as queimadas como causadoras dos problemas; quatro (13,33\%) informaram ser a falta de planejamento; três (10\%) disseram que é a falta de cuidado com o meio ambiente; dois $(6,66 \%)$ afirmaram ser a emissão de gases poluentes, a falta de preservação e a pecuária extensiva e um $(3,33 \%)$ aluno disse que se deve a ocupação dos espaços verdes. Como observamos no Gráfico 1. 


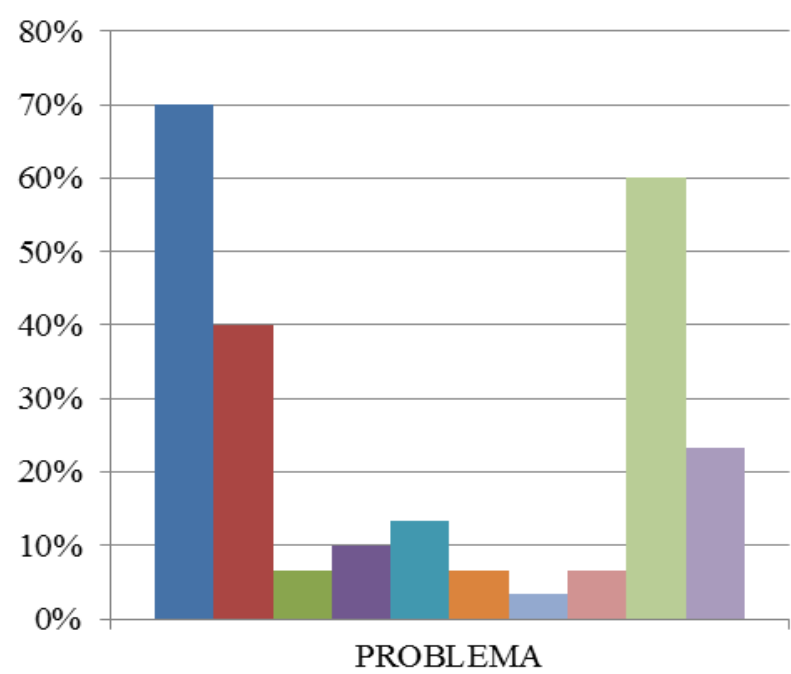

\author{
- Desmatamento \\ - Destinação incorreta dos \\ resíduos sólidos \\ Emissão de gases \\ poluentes \\ - Falta de cuidado com o \\ meio ambiente \\ - Falta de planejamento \\ - Falta de preservação \\ - Ocupação dos espaços \\ verdes
}

Gráfico 1. Percentual das respostas obtidas acerca dos principais problemas ambientais.

Percebemos que a maioria destacou termos que estão no auge dos propostos pela mídia e meios de comunicação, como desmatamento, poluição e destinação incorreta dos resíduos sólidos. Remetendo, dessa forma, que a mídia é um forte meio de sensibilização popular e que devia se utilizar mais desse meio para diminuir os problemas ambientais causados pelos alunos, seus familiares e comunidade no momento presente e, principalmente, no futuro, quando os alunos saem das universidades, penetram no mercado de trabalho e formam sua nova dinamicidade no contexto social com a consciência e a prática de um comportamento íntegro com a natureza e seus recursos, bem como a forma de ocupação e urbanização do espaço, a fim de alcançar um papel mais significativo na sociedade com relação ao meio ambiente.

Outro fato curioso observado nas respostas é a percentagem do tópico Queimadas, que atingiu o quarto lugar de mais citados (23,3\%). Supomos que isso se deve a maioria dos alunos entrevistados ser de cidades circunvizinhas (53,3\%), onde a ocorrência de queimadas é maior do que em uma cidade "mais urbanizada" que já teve grande parte de seu território ocupado pelas construções.

Na terceira questão perguntava "Em sua opinião, quem ou quais são os causadores destes problemas?”.

Nesta questão cada aluno podia citar quantos problemas ambientais quisessem. Acerca dos causadores desses problemas, 23 (76,66\%) alunos disseram que o principal causador dos problemas ambientais é a população; $14(46,66 \%)$ disseram que era o governo e seus gestores; 6 (20\%) disseram ser as indústrias; 1 (3,33\%) disse que era os agricultores e $1(3,33 \%)$ disse que não sabia. Como mostra no Gráfico 2. 


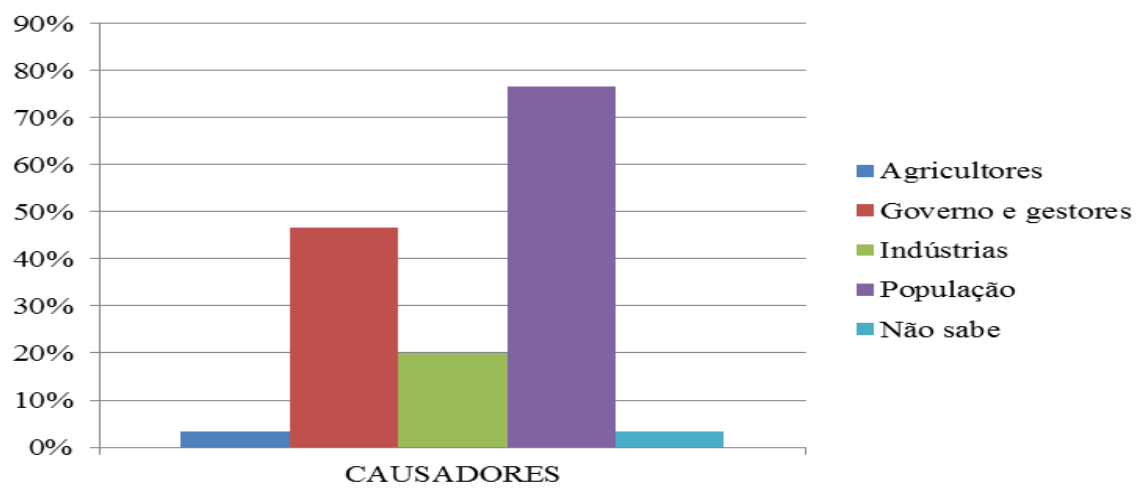

Gráfico 2. Percentual das respostas obtidas acerca dos principais causadores dos problemas ambientais.

Observamos que a maioria dos alunos elencou a população como o principal causador ambiental com 76,6\% das afirmativas, ou seja, muitos já têm submissa a ideia da parcela de culpa no que diz respeito à degradação do meio e as outras áreas citadas como causadoras dos problemas ambientais (Governo e seus gestores, Indústrias, etc) fazem parte e são "norteadas", também, pela população. Dessa forma, falta enaltecer esse senso em sua praticidade a fim de melhorarmos essa relação homem $\mathrm{X}$ meio ambiente.

Na quarta questão perguntava "O que você sente falta nas aulas, acerca das questões ambientais?”.

Observamos que quatorze (46,66\%) alunos disseram que sente falta de mais informações acerca das questões ambientais, sete $(23,33 \%)$ sente falta de desenvolvimentos de projetos, seis (20\%) de aulas práticas acerca dessa problemática, um (3,33\%) não sente falta e nada e dois $(6,66 \%)$ não responderam. Como mostra no Gráfico 3.

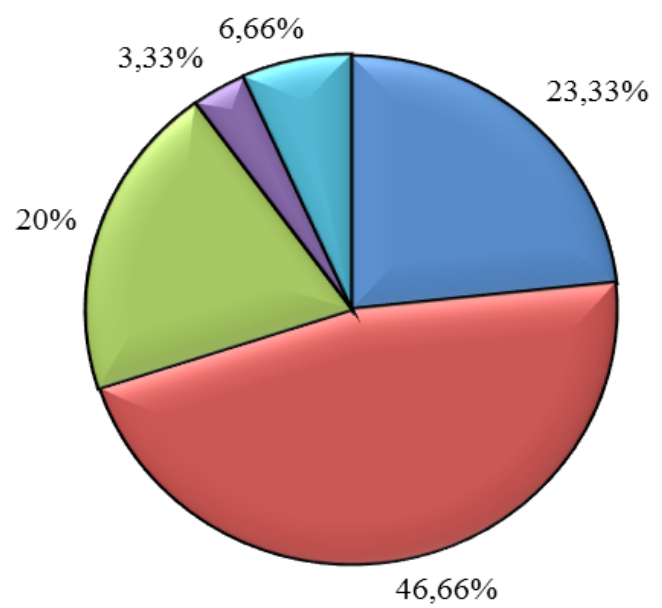

\section{DDESENVOL VIMENTO \\ DE PROJETOS \\ 口MAIS INFORMAÇÕES}

口AULAS PRÁTICAS

口NÃO SENTE FALTA DE

NADA

口NÃO RESPONDERAM

Gráfico 3. Percentual das respostas obtidas acerca dos componentes que fazem falta no decorrer do curso. 
Tabela 1. Categorias das representações das percepções do meio ambiente utilizadas na análise de dados.

\begin{tabular}{ll}
\hline Categorias & Descrição \\
\hline Romântica & Visão de “super-natureza”. Onde ilustra a natureza como grandiosa, harmônica, \\
& intocada, estática e equilibrada. Neste contexto o homem apresenta-se isolado e \\
& não inserido. Aponta uma visão dualista, homem vs. Natureza. \\
Utilitarista & Visão da natureza como a fornecedora de recursos as comunidades de seres \\
& vivos. Neste contexto, o homem apresenta inserido e o principal agente \\
& extrativista e beneficiado, apontando uma perspectiva antropocêntrica. \\
Abrangente & Visão holística que abrange um totalidade complexa que inclui os fatores \\
& naturais e antropocêntricos, resultando em uma relação entre os fatores bióticos, \\
& abióticos e socioeconômicos culturais. \\
Reducionista & Visão simplificada através dos aspectos biológicos e abióticos (físicos e \\
& químicos). Ignorando a complexa relação entre o meio e os demais sistemas \\
biológicos, sociais, econômicos e culturais. \\
Visão histórico-cultural, na qual o homem e a paisagem antropológica são \\
integradores da natureza. Ilustrando o homem muitas vezes como o principal \\
causador de impactos no ambiente.
\end{tabular}

Percebe-se que a maioria dos alunos se referiu à parte informacional acerca das questões ambientais nas salas de aula, condizendo que a resiliência ao impasse das informações se encaminha com as informações veiculadas no cotidiano e para que isso não se torne uma subjeção é necessário maior estimulação da pesquisa nas informações repassadas.

Outro fato importante é o desenvolvimento de projetos e formulação de aulas práticas para que o aluno formule o senso crítico e não fique refém da mídia no que diz respeito às questões ambientais como explica Tamaio (2000). Pois, a falta de alienação e ascensão da criticidade e da reflexibilidade nos faz perceber no tocante do meio ambiente e como poderíamos se comportar para que a relação homem $\mathrm{X}$ meio ambiente se torne acessível e saudável para as partes presentes nesse confronto, ou seja, eficiência na afinidade prevista.

Por isso, faz-se necessário maior estimulo e preocupação com a educação ambiental no curso analisado, visto que apenas 3,33\% dos alunos não sentem falta de nada acerca de tal problemática, percebendo que os alunos notam a omissão no engate da abrangência da questão ambiental no decorrer das aulas e das propostas advindas para o mesmo.

Na quinta questão perguntava "Qual medida você acha que seria relevante para melhorar o grau de percepção dos estudantes acerca dessa questão?”.

Dez alunos (33,3\%) disseram que uma medida relevante para melhorar o grau de percepção dos estudantes acerca das questões ambientais seria por meio da sensibilização, seis (20\%) disseram que seria por meio de aulas práticas acerca dessa problemática, quatro $(13,3 \%)$ elencaram palestras, quatro $(13,3 \%)$ disseram desenvolvimento de projetos, três (10\%) optaram pela adoção de uma disciplina eletiva acerca da problemática, um $(3,3 \%)$ disse que seria por meio de placas informativas e dois (6,6\%) deixou sem resposta. Como mostra no Gráfico 4. 


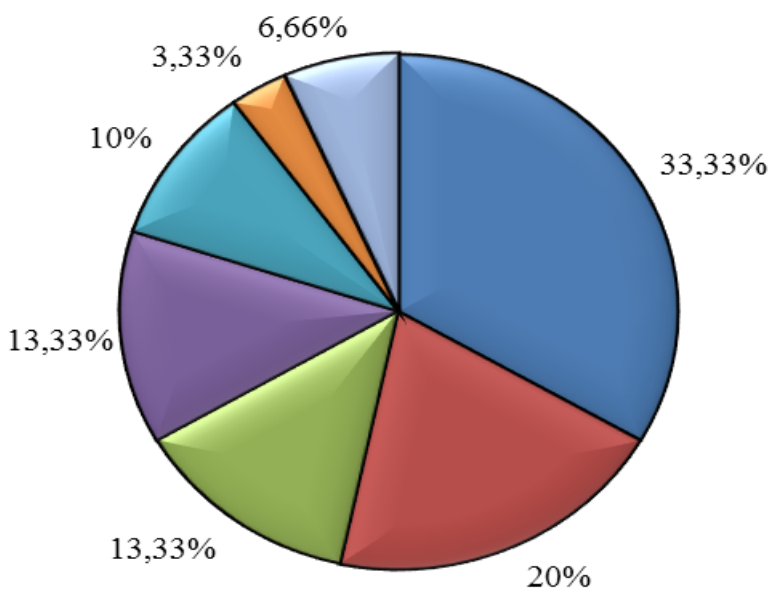

๑SENSIBILIZAÇÃO

口AULAS PRÁTICAS

DPALESTRAS

口DESENVOLVIMENTO

DE PROJETOS

口DISCIPLINAS

ELETIVAS

DPLACAS

INFORMATIVAS

口SEM RESPOSTA

Gráfico 4. Percentual das respostas obtidas acerca do que seria relevante para melhorar o grau de percepção.

Percebemos que a maioria dos alunos disse que uma medida relevante para melhorar o grau de percepção dos estudantes no que diz respeito às questões ambientais é a sensibilização do mesmo. No entanto, não especificaram qual medida seria necessária para obter essa "sensibilização". Dessa forma, adotaremos como medida sugerida pelos estudantes do curso de Geografia para a sensibilização dos mesmos as aulas práticas que obtiveram $20 \%$ das sugestões. E, segundo Krasilchik (2008), as aulas práticas cooperam com a melhoria da qualidade da aprendizagem de um determinado saber. Com isso, é propicio a melhoria da qualidade e da compreensão do meio em que vivemos, pela utilização e abordagem dessa metodologia no decorrer das aulas.

Na sexta questão perguntava "A questão ambiental é tratada com ênfase durante as aulas no seu curso?”.

Acerca das questões ambientais serem tratada com ênfase no decorrer do curso, treze alunos responderam que sim (43,33\%), doze responderam que sim, mas não com muita ênfase (40\%) e cinco disseram que não (16,66\%). Como mostra no Gráfico (5).

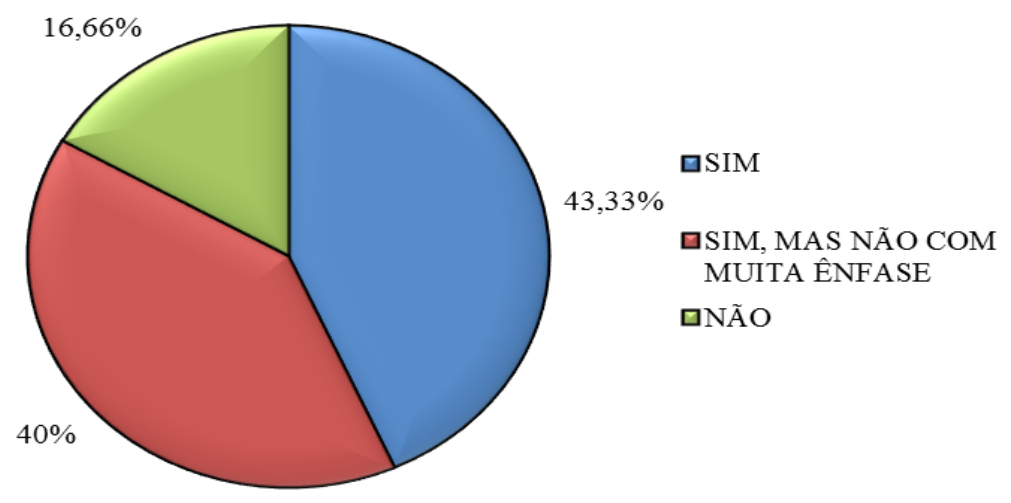

Gráfico 5. Quantidade de respostas obtidas acerca da ênfase na qual as questões ambientais são tratadas em sala de aula. 
Observamos que 43,3\% (13 alunos) dos alunos disseram que as questões ambientais são tratadas com ênfase no curso de Geografia da UEPB.

Observamos que o número de alunos que responderam "sim" e os que responderam "sim, mas não com muita ênfase" foram aproximados. Isso pode nos fornecer certo grau de conformidade dos alunos com o presente no qual estamos inseridos, visto que nas questões quatro e cinco eles apontaram ajustes a serem feitos no decorrer das aulas para que se prime com uma educação ambiental de qualidade e eficiência, só que ao mesmo tempo a grande parte dos alunos (43,3\%) mostra satisfação com o exposto. Por isso esse paradigma precisa ser quebrado com a adoção de métodos mais eficazes para superação desse impasse.

\section{CONCLUSÃO}

Diante do exposto, observamos que a percepção dos estudantes do curso de Geografia (licenciatura) da Universidade Estadual da Paraíba acerca das questões ambientais não é significativamente diferente do resto da população acerca dessa questão, visto que a interferência do meio, muitas vezes, é mais alta do que as concepções adquiridas em sala de aula, como constatamos pelas respostas adquiridas na segunda e terceira questão. Porém, se diferencia pelo período em que o aluno se encontra como observamos no primeiro quesito.

Acerca das distintas respostas dos alunos presentes no inicio do curso $\left(2^{\circ}\right.$ período) em comparação com os alunos no final do curso ( $7^{\circ}$ período) observamos que houve uma melhoria em termos de amplificação e consistência das respostas obtidas pelo período mais avançado em relação ao inicial, condizendo que as aulas ministradas no decorrer do curso influenciaram positivamente na percepção ambiental.

No tocante a percepção dos alunos acerca da abordagem das questões ambientais apresentadas no decorrer do curso verificou que as aulas desenvolveram muitas concepções positivas aos alunos acerca do tema problema, mas, na totalidade verificamos que ainda faz-se necessário o desenvolvimento de uma educação ambiental mais elaborada para que a percepção da mesma melhore na concepção dos alunos, bem como na tentativa de melhorar os indicadores de qualidade ambiental nos espaços que os mesmos se fazem presentes.

\section{REFERÊNCIAS}

BEZERRA, T. M. O., GONÇALVES, A. A. C. Concepções de meio ambiente e educação ambiental por professores da Escola Agrotécnica Federal de Vitória de Santo Antão-PE. Biotemas, v. 20, n. 3, p. 115-125, 2007.

BORTOLOZZI, A.; PEREZ FILHO, A. Educação ambiental e reconstrução da cidadania. Revista Sociedade e Natureza, v. 6, n. 11-2, 1994.

BRÜGGER, P. Educação ou adestramento ambiental? Florianópolis: Letras Contemporâneas, 1994. (Coleção Teses).

GONÇALVES, C. W. P. Reflexão sobre geografia e educação: notas de um debate. Fundamentos para o ensino de geografia. São Paulo: CENP, 1992.

KRASILCHIK, M. Prática de Ensino de Biologia. 4. ed. São Paulo: EdUSP, 2008.

MOTTA-ROTH, D.; HENDGES, G. R. Produção textual na universidade. São Paulo: Parábola, 2010. (Série Estratégicas de Ensino, 20).

ROSA, L. G., SILVA, M. M. P. 2002. Percepção ambiental de educandos de uma escola do ensino fundamental. In: SIMPÓSIO ÍTALO BRASILEIRO DE ENGENHARIA SANITÁRIA E AMBIENTAL, 6, 2002. Vitória. Anais... 2002. 
XAVIER, A. C. Como fazer e apresentar trabalhos científicos em eventos acadêmicos. Recife: Respel, 2010.

TAMAIO, I. A mediação do professor na construção do conceito de natureza: uma experiência de Educação Ambiental na Serra da Cantareira e Favela do Flamengo/São Paulo. Campinas: Universidade de Campinas, 2000. (Dissertação de mestrado). 